\title{
Fundamentos teóricos epistemológicos de los territorios discursivos
}

\author{
Theoretical epistemological foundations of discursive territories
}

Sandra Villanueva-Gallardo (svillanuevagallardo@gmail.com) Centro de Estudios del Desarrollo Regional y Políticas Públicas, Universidad de Los Lagos (Osorno, Chile) ORCID: 0000-0001-5594-7216

\begin{abstract}
This work focusses on giving an account of the existence of a territory other, made invisible by the logocentrism and the traditional historiography of the modern west. This territory other that we call discursive territories is a reality that we situate in territorial discourses and that, given its discursive dimension, can be revealed through hermeneutical analysis. One of the assumptions on which this research is based, is that the discursive territories act as the place from which the territorial discourse becomes what it is, to indicate a direction and to specify a specific meaning, in any of the forms institutionalized by a collectivity (poetry, religion, politics, economy, culture, etc.) but without full awareness or evidence of it. Therefore, we propose that the discursive territories are linked to the hologram image, a condition that we suggest is revealed from a sociocultural background and through the hermeneutic interpretation of territorial discourses.
\end{abstract}

Key words: territory, hologram, diatopical, hermeneutics, recursion, meaning, discourse.

\section{Resumen}

El trabajo se centrará en dar cuenta sobre la existencia de un territorio otro, invisibilizado por el logocentrismo y la historiografía tradicional del occidente moderno. Este territorio otro que denominamos territorios discursivos es una realidad que situamos en los discursos territoriales y que, dada su dimensión discursiva, puede ser develada mediante el análisis hermenéutico. Uno de los supuestos en que se basa esta investigación, es que los territorios discursivos actúan como el lugar desde el cual el discurso territorial llega a ser el que es, a indicar una dirección y explicitar un sentido específico, en cualquiera de las formas institucionalizadas por una colectividad (poesía, religión, política, economía, cultura, etc.) pero sin que se tenga plena conciencia o evidencia de éste. Por lo anterior, planteamos que los territorios discursivos se encuentran ligados a la imagen hologramática, condición que proponemos develar desde un trasfondo sociocultural y por medio de la interpretación hermenéutica de los discursos territoriales.

Palabras clave: holograma, territorial, hermenéutica, diatópica, recursividad, sentido, discursos.

\section{Introducción}

Tanto el territorio como la territorialidad han sido conceptos tratados teóricamente desde sus dimensiones materiales y simbólicas, sin embargo, parece existir un mayor acercamiento a comprender y dilucidar culturalmente a la territorialidad que al propio territorio. En otros términos, se visualiza la tendencia a entender que la apropiación de los espacios y lugares contempla distintas y múltiples 
relaciones bajo una misma concepción epistemológica. Lo anterior, se relaciona con uno de los aspectos que la corriente decolonial denomina colonialidad del saber, es decir, "el posicionamiento del eurocentrismo como la perspectiva única del conocimiento, la que descarta la existencia y viabilidad de otras racionalidades epistémicas y otros conocimientos que no sean los de los hombres blancos europeos o europeizados" (Walsh 2008:137). En este sentido, señalamos que dicha colonialidad del saber también afecta al entendimiento de los territorios, siendo este el lugar desde el cual trazamos nuestro enfoque.

Planteamos que la relación territorio y discurso ha sido comprendida bajo categorías analíticas apartadas de los procesos de conformación social del territorio, dicho de otro modo, como un discurso que da cuenta de las características de un territorio o un territorio que, para ser capturado, debe dar cuenta de los discursos y de las prácticas cotidianas asociadas a los sujetos que lo habitan. Por tanto, ha sido infrecuentemente tratada desde una mirada epistemológica que los vincule como elementos recursivos en tanto construcciones sociales que son. De esta manera, en el área más simbólica del territorio, como por ejemplo la geografía humana, si bien se invierten los papeles entre materialidad e inmaterialidad, no se elimina la linealidad de la determinación causal. Entonces, el pensamiento en primer término (y actualmente el discurso) será determinante para la realidad del territorio.

Al presente, por el contrario, la crisis de la modernidad ha llevado a cuestionar y ampliar las interpretaciones sobre los territorios y la territorialidad, dejando a un lado las premisas reductoras que señalaban relaciones unilineales y fragmentarias, avanzando hacia una comprensión de co-determinación donde los "productos y los efectos son, al mismo tiempo, causas y productores de aquello que los produce" (Morin 1996:67).

A partir de este marco general, consideramos como tradición al pensamiento moderno, principalmente positivista, en su interés de justificación de la simplicidad, y como pensamientos complejos a las corrientes actuales de la reflexión crítica latinoamericana guiada preferentemente por el pensamiento fronterizo, en conjunción con aspectos teóricos de las epistemologías del sur.

En estos contextos pensamos las relaciones del territorio y el discurso, para visualizar allí los principios que proponemos como ejes centrales de los territorios discursivos, enunciados claves para la comprensión y estudio de los discursos territoriales que nos preocupan, así como para sentar las bases para una proyección cultural que pueda considerarse como diálogo intercultural.

\section{Metodología}

Para dilucidar los principios de los territorios discursivos (TDs) como condicionantes del sentido que los territorios tienen para los sujetos sociales y que aparecen expresados en sus discursos territoriales, nos proponemos delimitar epistemológicamente el constructo realizando los siguientes pasos: 1) Revisión teórica del tratamiento de la relación de territorio y discurso en las principales bases de datos del mundo académico, con el fin de buscar los puntos significativos en investigaciones recientes sobre la temática, 2) antecedentes sobre dicha relación teórica, a modo de diagnóstico en cuanto a los elementos significativos tratados por otros autores, 3) en función del diagnóstico, plantear la interrelación entre territorio-discurso, incorporando los fundamentos teóricos epistemológicos que proponemos como base de los territorios discursivos.

La relación teórica entre territorio y discurso ha sido estudiada desde varias aristas y de ellas se han elaborado varias propuestas de análisis, entre las que podemos sintetizar cuatro corrientes principales: (1) 
el territorio como categoría analítica del discurso es una de las perspectivas donde es posible visibilizar diversos trabajos de investigación, empleando el enfoque metodológico del análisis hermenéutico del discurso, donde los conceptos de territorio y discurso no aparecen necesariamente como elementos explícitos, sino como alusiones teóricas. En estas dimensiones, el territorio está en una relación de subordinación del discurso o viceversa, dependiendo de la óptica que adopte el hermeneuta. Aquí, figuran las coordenadas de N. Vergara que plantean que "interpretar el territorio es entonces indagar en lo profundo de esas significaciones inscritas en el decir y posibilitadas por el decir" (Vergara 2009:239), siendo este uno de nuestros puntos teóricos de partida y además una de nuestras consideraciones metodológicas fundamentales.

Esta primera perspectiva tiene aspectos que se asemejan a lo planteado en nuestra investigación. Aquí, el discurso se vincula al territorio como unidad de análisis, donde éste último es posible de caracterizar y de ser interpretado. Sin embargo, se visualizan como elementos distintos en su materialidad, es decir, el discurso como el factor intangible que da cuenta de aspectos materiales del territorio. En cambio, nuestra investigación señala que las nociones colectivas del territorio están imbricadas al discurso y, por tanto, se está erigiendo no solo un discurso territorial como lo señala esta vertiente, sino un territorio discursivo socialmente conformado.

(2) Otra dimensión de análisis concierne al discurso oral y/o escrito como antecedente que aporta, en conjunto con las prácticas de los sujetos, en la elucidación de sus proyecciones futuras y trayectos pasados. Esta manera de concebir al discurso en concomitancia a otras actividades es la utilizada para el análisis y caracterización de los imaginarios territoriales, donde las memorias, vivencias e imaginarios de los sujetos son puestos en relación de coherencia junto a sus actividades cotidianas para elucidar "la creatividad de los grupos y su forma de percibir el mundo para actuar en él" (Ther 2012:503). En esta dimensión, el discurso se encuentra en relación de subordinación al territorio.

Si bien la teoría de los imaginarios territoriales presenta aspectos compartidos con la propuesta de TDs, ya que ambas sitúan el ámbito de realidad en lo imaginario, igualmente ésta se distancia en un supuesto base de nuestra investigación. Nuestro planteamiento inicial es que en el discurso territorial (oral, escrito, iconográfico) existe un sentido de identidad territorial no develado, que actúa como principio epistemológico condicionante de estos discursos. La construcción social de esta controversia se evidencia, con mayor intensidad, en los discursos provenientes de comunidades o pueblos con características cosmológicas distintas a occidente, como es el caso del pueblo mapuche, donde las significaciones territoriales de sus discursos desbordan el ámbito de lo imaginario. Estos análisis se conectan con los planteamientos realizados por el constructivismo geográfico que permiten comprender al lugar "como un mosaico de lugares que han sido y son construidos socialmente, en un proceso siempre inconcluso" (Lindón 2007:6).

El entendimiento del territorio como un mosaico de posibilidades, sumado a la idea de proceso inacabado, nos posibilita la existencia de un tipo de territorio que posiblemente no coincide con las prácticas territoriales, con los lugares materialmente habitados, con las formas y límites conocidos, siendo una manera de acceder a ellos, por medio de la interpretación hermenéutica de los discursos asociados a los sujetos que piensan y, en nuestro caso, discursean sobre estos territorios otros.

(3) Discursos territoriales como narrativas que dan cuenta de las identidades territoriales. Aquí, las memorias orales y escritas se transforman en fragmentos de experiencias de los sujetos colectivos que a su vez conforman la historia del territorio. La problematización que alude esta corriente guarda relación 
con el vínculo territorio-identidad, tendencia ligada al ámbito cultural, donde la construcción identitaria está marcada por las memorias de los habitantes, por tanto, sus recuerdos traspasados a discursos son contenedores de aspectos identitarios que se conectan con un lugar determinado. Sobre esta dimensión, el territorio es lo que el discurso dice que es, por cuanto se visualiza la subordinación del territorio al discurso.

En cuanto a esta tercera corriente de relación podemos localizar lugares de encuentro con nuestra investigación. La memoria colectiva y la conformación de identidades territoriales que se expresan discursivamente es una categoría común, no obstante, nuestra propuesta recursiva entre territoriodiscurso supera las tradicionales dicotomías binarias donde un elemento (el discurso) determina las características del segundo aspecto (el territorio), apuntando a su co-determinación, basándonos para ello en el desarrollo del pensamiento complejo elaborado por E. Morin.

(4) El discurso político como una manifestación territorial sobre lo que se piensa, imagina y se dice con respecto a los espacios y lugares. En esta visión relacional, se comprende al discurso político como un emisario explícito que demanda sobre la caracterización homogénea del territorio una especie de contenedor explicativo del ideario territorial. En este sentido, el discurso es tratado como un medio útil de expresión, encontrándose como elemento subordinado al territorio.

En este enfoque encontramos una mirada utilitaria que adoptan los discursos, donde formatos textuales tales como los enunciados políticos están refiriendo consciente y explícitamente lo que se piensa del territorio. Se señala que esta dirección aporta una perspectiva de análisis relevante, pues no es premisa de este estudio plantear que los territorios estarían solo en unidades discursivas colectivas inconscientes, no obstante, postulamos que por medio de los territorios otros es posible llegar a una mejor comprensión intercultural, donde los sujetos colectivos son parte de la construcción y entendimiento de los espacios y lugares que los conforman identitariamente.

El diálogo que esta investigación pretende extender, por medio de estas cuatro vertientes de relación, se ciñe a una postura epistemológica. El discurso en las cuatro posturas mencionadas es vista como una representación, donde los sujetos sociales entregan elementos significativos sobre sus territorios, como aspectos separados que pueden presentar más o menos conexión entre uno y otro, sin embargo, no consideran la posibilidad que el territorio representado discursivamente, esté erigiendo un espacio territorial recursivo, con características territoriales igualmente válidas que las concepciones hegemónicas actuales y que, aún más, sean realmente las referencias epistemológicas condicionantes de todo discurso territorial.

\section{Antecedentes}

Actualmente, en los estudios referidos a los últimos seis años, sobre la relación territorio-discurso, se encuentran resultados que presentan vínculos de correspondencia, donde las identidades se transforman en un concepto clave, pues se alude a la comprensión del territorio por medio de los discursos emitidos por sujetos sociales. Aquí aparecen investigaciones postcoloniales relacionadas a diferentes ámbitos identitarios, como es el caso mapuche, tal como lo señala P. Castro (El discurso mapuche en la era poscolonial identidad, territorio y poder). También Nieto, García, Martín y Nicasio (De la pobreza a la marginación) plantean las configuraciones de identidades excluidas por la pobreza y la marginalidad social. Además, J. Williams (La construcción del pasado chubutense en el discurso histórico provincial) traza la emergencia del rol de los discursos territoriales en la comprensión de las identidades nacionales y la 
relación de pertenencia a un determinado lugar. Asimismo, la dimensión política del territorio es indagada a través de discursos de actores claves, quienes dan cuenta de las dinámicas al interior de un lugar, como describe T. Mouries (¿Con o sin ancestros?).

Por otra parte, D. González (Espacios y territorio en la propaganda y en los discursos durante los conflictos bélicos) visibiliza los intereses hegemónicos de España en los discursos políticos y religiosos acerca del territorio en épocas beligerantes y Guazzelli-Bernardes (Território e acesso) configura el análisis de las políticas de salud en Brasil y su articulación con el territorio, considerando el perfil epidemiológico que circunscriben.

Una segunda cuestión recurrente en las investigaciones actuales sobre la relación territorio-discurso se encuentra ligado al ámbito de los conceptos de desarrollo y medioambiente. En esta dimensión aparecen estudios contextualizados principalmente en distintas partes de América Latina, como por ejemplo Colombia, donde M. Pérez (Discursos ambientales) afirma que el discurso medioambiental, construido sobre el Parque Nacional Natural de Colombia, se erige como un discurso del territorio y del desarrollo que involucra un sector más amplio que el lugar específico al cual se refiere.

Desde otra perspectiva, Aliste y Musset (Pensar los territorios del desarrollo) estudian las transformaciones territoriales que se expresan en discursos que dan cuenta de una visión de progreso, situando la discusión en las condiciones medioambientales actuales, como por ejemplo en Chile, específicamente en la ciudad de Concepción. También se replica la interpretación en el archipiélago de Chiloé, donde J. Moreno (Redes y estructuras familiares en la experiencia del territorio) analiza las características actuales de las familias chilotas en virtud de la influencia que ello experimenta en la forma de vivir los territorios contemporáneos.

Del mismo modo, H. Schiaffini (Pertenencia, territorio y defensa) revisa cómo algunos sectores específicos de las poblaciones locales de México y Argentina perciben la propuesta y el desarrollo de la actividad minera por medio de discursos claves. Por su parte, S. Herrera (Del progreso a la armonía) realiza un recorrido por los discursos de las principales naciones, corporaciones y organismos internacionales de principios del siglo XXI para develar las visiones hegemónicas del entendimiento de la relación sociedadnaturaleza. Y dentro de lo más reciente encontramos el artículo de Garduño y Sting (Desarrollo, mito y discurso) quienes analizan el trayecto de la noción de desarrollo en los procesos discursivos, llegando a la conclusión que el discurso es un medio reificador que lleva a definir al sujeto como un individuo con identidad basada en sus hábitos de consumo.

Las metodologías empleadas por estos estudios se encuentran entre el análisis del discurso y la interpretación hermenéutica, donde se incorporan técnicas y perspectivas de análisis que complementan los discursos de los actores sociales, como es el caso de la etnografía, la semiótica, el análisis literario y la fenomenología. Las principales conclusiones que se develan por medio de estas herramientas se inclinan a dos ámbitos que resumimos de la siguiente manera: (1) los discursos, sean políticos, identitarios, literarios o de desarrollo, son una expresión del territorio, sobre todo en sus aspectos simbólicos, los cuales de alguna forma tienen incidencias en los modos de ser y habitar en los espacios y lugares. (2) Dentro de la complejidad de los territorios, los discursos se erigen como una vía de acceso hacia la comprensión de los sujetos sociales que viven en un determinado lugar.

En consecuencia, la relación actual entre discursos y territorios no configura un espacio territorial, porque no se les ha pensado desde una dimensión recursiva. De esta manera, podemos evidenciar que la 
propuesta de interrelación mutua entre territorio y discurso es un proyecto no visibilizado aún en las investigaciones occidentales, tanto en los ámbitos teóricos como metodológicos.

\section{Principios teóricos epistemológicos de los territorios discursivos}

A partir de la revisión anterior, nos centraremos en la noción de territorios discursivos y a la propuesta de una realidad territorial latente en los discursos. En este contexto es preciso destacar que no aludimos a otros territorios más de los actualmente reconocibles, sino a territorios distintos con una naturaleza emergente desde una postura epistemológica específica, la que hemos denominado territorios otros. Este último concepto se encuentra invertido en el orden tradicional de la frase, justamente porque no añadimos solo otro espacio territorial, sino que proponemos una realidad hologramática distinta e invisibilizada por el logocentrismo y la historiografía tradicional del occidente moderno. Con este propósito en mente, desarrollamos ocho principios teóricos epistemológicos que darán, posteriormente, origen a los TDs y que delimitamos de la siguiente manera.

\section{Los territorios discursivos desde las epistemologías del sur}

La epistemología en la que se enmarca la definición del concepto de TDs corresponde a las epistemologías del sur (ES) desarrollada principalmente por B. Santos. Esto porque, a partir del posicionamiento político y lugar de enunciación desde el cual se pretende dar cuenta de una alternativa territorial distinta y negada por las condiciones de inferioridad normativa planteadas por occidente, permite comprender que la racionalidad a la que se apela es proveniente desde una perspectiva crítica y descolonizadora.

El abordaje epistemológico que planteamos es requerimiento fundamental para lograr dar cuenta de los TDs en su categoría de realidad territorial, con formas, relieves y fronteras y no así, sean situados exclusivamente en el ámbito imaginario.

Este marco de conocimiento se conjuga con los enfoques provenientes desde la corriente decolonial y los estudios subalternos, donde abordamos principalmente las nociones de pensamiento fronterizo de G. Anzaldúa, la sociología de las imágenes de S. Rivera Cusicanqui y la colonialidad del saber de E. Lander, conjunto teórico que permite abordar la relación territorio y discurso desde un análisis coherente con la búsqueda de rasgos territoriales invisibilizados.

\section{Los territorios discursivos como proceso hermenéutico}

El empleo de las ES conlleva a la exploración de metodologías afines y en este contexto surge la hermenéutica diatópica como herramienta interpretativa para analizar los discursos territoriales. Esta elección metodológica refiere a una opción vinculada con los objetivos planteados en cuanto a la ampliación teórica del tratamiento de territorio como categoría analítica y concepto asociado a las distintas maneras de ser y habitar de los seres humanos. Lo anterior quiere decir que los TDs son susceptibles de ser analizados por otras hermenéuticas enmarcadas en otras epistemologías, sin embargo, nuestra elección permite avanzar con mayor precisión, aunque nunca con garantías absolutas, sobre la descripción y comprensión de territorios ocultos a la mirada más racional, empírica y moderna.

El trabajo de intelección que proponemos para la elucidación de los TDs involucra, ciertamente, un análisis hermenéutico de los discursos territoriales, entendidos estos últimos como todas aquellas manifestaciones orales, escritas e iconográficas que entregan información o refieren sobre los distintos 
espacios y lugares. De esta manera, planteamos que lo que se dice respecto del territorio aborda diferentes dimensiones narrativas que van desde el relato oral, pasando por el texto escrito y llegando a las expresiones icónicas mediante dibujos o imágenes de los territorios. Por ende, consideramos relevante abarcar estas tres dimensiones para la elucidación territorial-discursiva que formulamos.

Por otra parte, pensamos a la hermenéutica diatópica equitativa a nuestros propósitos, pues nos permite ser coherentes en razón de la crítica a la colonialidad del saber que ha involucrado la restricción y comprensión de los distintos territorios. Esto, debido principalmente a la idea de base que esta metodología involucra y que nuestra investigación releva por su carácter epistémico, la cual consiste en el reconocimiento del otro en su categoría de sujeto de conocimiento, es decir, no un objeto de estudio que entrega información al investigador, si no a la propensión del diálogo horizontal y valorativo tanto de la información como del proceso de interpretación del cual también es parte relevante. La declaración éticapolítica realizada por la hermenéutica diatópica actúa como principio metodológico que vigila la inclusión y respeto por las distintas maneras de entender los territorios.

Aquello está relacionado con las ideas más actuales del pensamiento crítico latinoamericano que estimulan investigaciones y metodologías efectivamente descolonizadas, lo que se ve materializado en esta hermenéutica en el posicionamiento horizontal entre los actores que participan de la interpretación y la búsqueda de los lugares comunes en los discursos para el establecimiento de un diálogo intercultural.

\section{Recursividad entre territorio y discurso}

Para situarnos en la comprensión de los TDs hay que posicionarse críticamente frente a la modernidad, específicamente frente a las formas binarias, concebidas por polos opuestos, para acceder a los distintos conocimientos y buscar desde una postura que permita la recursividad entre los conceptos de territorio y discurso.

El proceso de construcción de los TDs se presenta anclado en los discursos territoriales de sujetos sociales. En ellos es posible distinguir elementos descritos por las distintas líneas de la geografía humana, como son ciertas conexiones temporales con el espacio o intersticios con las fronteras físicas, sin embargo, existen elementos que aparecen en los discursos que no concuerdan con la descripción física de éste, figurando como elementos de carácter ficticio o únicamente imaginarios. En esta contradicción nos situamos para la interpretación de los TDs, pues la discrepancia entre el discurso territorial y la práctica material del territorio como evidencia física de qué es y cómo está constituido, no niega la condición de realidad.

Nuestro planteamiento es que el hecho que existan marcas y tendencias discursivas repetidas en grupos o comunidades que refieren sobre sus territorios y que dichas marcas no coincidan con la descripción oficial, nos habla de una realidad territorial que devela características invisibilizadas por la imposición epistemológica occidental que coloca al discurso en subordinación a los territorios.

Los discursos, en esta investigación, se plantean como fuente de interpretación de la realidad territorial porque dejan de manifiesto imágenes hologramáticas, con tiempos específicos, espacios particulares, límites y emociones compartidas colectivamente, todo lo cual conecta esta geografía con la identidad territorial de los sujetos que expresan estos discursos, porque las características contenidas en estos relatos hablan de un sitio en particular, en consecuencia, lo que allí se devela son características de un lugar entendido como propio, expresándose la territorialidad y la identidad comunitaria del espacio. 
Esta línea de análisis, diferencia la realidad de los TDs de la literatura, pues no se configura con la ficción de un individuo, sino con el análisis colectivo y el encuentro de marcas textuales o lugares comunes. En suma, los discursos territoriales analizados como un cuerpo interpretativo de elementos compartidos por la colectividad se encuentran en relación de recursividad con los territorios.

\section{Carácter plural de los territorios discursivos}

Dado que ninguna cultura es en extremo singular, sino más bien son sus características heterogéneas las que componen sus identidades, así como sucede con las distintas maneras de percibir y enunciar los territorios, convendría la concepción plural de los territorios discursivos para que den cuenta de las diversidades de posibilidades, incluyendo potenciales TDs distintos o contrapuestos, operando en un mismo discurso territorial. Ello expone las posibles controversias, donde ciertos discursos hegemónicos se impondrán sobre otros, aproximándonos a TDs dominantes y emergentes, dependiendo de la situación sociohistórica de la colectividad expresada.

\section{Los territorios discursivos en sus contextos de producción}

Las imágenes hologramáticas presentes en los TDs están relacionas con la noción de tiempo. En ellas se habla de un territorio concebido en la memoria, de un pasado que se rememora con las diferentes emociones que ello puede acarrear. Este pasado puede estar concebido desde los recuerdos de la infancia a proyecciones utópicas de lo que a los sujetos sociales les hubiese gustado que fuere. Por otra parte, pueden atraer visiones ideales y/o no deseadas del futuro, un territorio que camina hacia una transformación imaginaria basada en los deseos o frustraciones colectivas, planteando una realidad territorial temporalmente presente que puede ser el resultado de la combinación de todas o de una de las situaciones pasadas o futuras anteriores.

Los TDs responden a contextos de producción específicos, en otros términos, dependen de las características agrupadas de los sujetos de una determinada época. Estos se modifican dependiendo del lugar y tiempo en los cuales se producen y se quedan momentáneamente estáticos en el momento de su interpretación hermenéutica. Aunque, también es preciso aclarar que dicha interpretación, siempre va a ser el resultado de una aproximación que intentará acercarse a la descripción y comprensión de estos territorios.

\section{Sentido de identidad territorial en los discursos}

Hemos planteado desde un comienzo el origen discursivo de estos territorios, no obstante, las marcas que establecemos como relevantes para su elucidación están asentadas en dos líneas de significación que reconoceremos por sus puntos de fuga en los discursos, es decir, por manifestarse como aspectos del relato oral, escrito o iconográfico que se escapan del discurso predominante. De esta manera, nos encontraremos con 1) marcas afectivas en torno a los territorios (nostalgia, amor, odio, desprecio, indiferencia) que indiquen conexión o desconexión con un determinado lugar, 2) memoria colectiva traducida a elementos discursivos que contengan aspectos recurrentes y de alta carga significativa con respecto al territorio, esto es, que se repitan en el relato y/o que simbolicen algo para la propia cultura, 3) mapas mentales del territorio, imágenes que sean plasmadas por los sujetos que definen a un territorio en particular. 
Consideramos que el análisis de estas tres dimensiones en la construcción del relato colectivo nos permitirá interpretar el sentido de identidad presente en los TDs para posteriormente, interceptarlo con las imágenes contenidas en el holograma territorial que da forma a esta alternativa epistemológica.

\section{Los territorios discursivos son una realidad imaginaria}

Al comprender los TDs como realidades imaginarias estamos señalando, por una parte, que son reales para los sujetos colectivos que se identifican con un territorio específico, y, por otra que el ámbito en que estas realidades se materializan no es del orden de lo tangible, ni de lo conceptual, sino del mundo de lo imaginario en tanto constitutivo de la condición humana. Por ello, los TDs se encuentran en permanente construcción por sujetos sociales, al tiempo que éstos son, sociohistóricamente, construidos por ellos. Es claro que esta co-construcción sociohistórica se realiza, la mayoría de las veces, de manera no consciente, por lo que tampoco opera conscientemente su discursividad. Por consiguiente, los TDs actúan como condicionante para que todo discurso territorial llegue a ser el que es, a tomar una forma e indicar un sentido específico, en cualquiera de las formas institucionalizadas por una colectividad (economía, religión, política, cultura, arte, etc.) lo que no quiere decir que sean imágenes territoriales homogéneas, sino que son construcciones sociales con características diversas, las que son posibles de rastrear mediante un trabajo hermenéutico de interpretación de estos discursos.

\section{Conformación del holograma territorial-identitario}

La intersección teórica-metodológica que consideramos clave para la elucidación de los TDs consiste en dos etapas. 1) La primera es la interpretación hermenéutica de los discursos territoriales para determinar el sentido de identidad presente en estos discursos. Este proceso lo exteriorizamos mediante la ubicación de los lugares comunes dentro de los relatos colectivos, propuesta que desarrolla la hermenéutica diatópica y que radica en la identificación de los argumentos territoriales utilizados como elementos de base, enunciados que están implícitos en los demás argumentos o afirmaciones que no son tema de discusión para la propia cultura, actuando como supuestos transversales a toda discusión.

2) Una vez que obtenemos la interpretación del sentido de identidad territorial, nos valemos de la teoría de los hologramas espaciales de A. Lindón, donde situamos la relación entre la producción de imágenes de sujetos sociales y la realidad imaginaria en que se sostienen dichas imágenes, entendidas como "tramas de significaciones y sentidos que están inmersas en/con el mundo" (Lindón 2012:12). Los imaginarios son entonces una entrada teórica condicionante de los hologramas espaciales, como escenario en el cual ubicamos la condición de realidad de los TDs. Para ello, seleccionamos las perspectivas analíticas de G. Bachelard y G. Durand, pues ambos realizan el abordaje de lo imaginario desde el tratamiento de las imágenes.

Consideramos que esta intersección analítica da cuenta de cómo la narratividad, la memoria contendida en los discursos sobre los territorios, en conjunto con las afectividades territoriales, son interpretables hermenéuticamente, no por cualquier hermenéutica, sino por una en particular que sitúa el diálogo intercultural desde un posicionamiento epistemológico que busca el respeto y valoración de los sujetos de conocimientos. Dicha interpretación no queda en un análisis del discurso territorial, sino que avanza a la imagen que los registros discursivos (orales, escritos e iconográficos) configuran, aunando de esta manera dos aspectos centrales de la teoría de los imaginarios: los discursos y las imágenes. 


\section{Conclusiones}

En este camino hemos establecido las condiciones fundamentales para la emergencia de TDs en su naturaleza recursiva, donde develamos las características hologramáticas, imaginarias e identitarias que la componen.

La búsqueda central es el establecimiento de las bases epistemológicas de un territorio que parte de definiciones territoriales no impuestas y preestablecidas, donde la inmaterialidad de la palabra es cuestionada como categoría intangible, siendo el discurso comprendido como un elemento indisociable de los territorios.

Los TDs desde las epistemologías del sur son una co-construcción entre los sujetos portadores de identidades territoriales y la investigación, los que procuran dar cuenta de la intersubjetividad que fluye en la heterogeneidad presente en los territorios y que se manifiesta por medio de los discursos. De esta manera, el territorio visto desde la perspectiva de la identidad (entendiendo las multiplicidades de identidades y la complejidad de éstas en términos individuales, colectivos e intersubjetivos) es un concepto que plantea formas, relieves y profundidades que no han sido todas develadas. El territorio está en aspectos físicos e inmateriales. ¿Quién determina cuáles son los mecanismos en que lo material prima ante lo intangible? Volcar o equiparar la importancia de los aspectos simbólicos frente a los elementos concretos del territorio es una alternativa a lo ya existente y es la propuesta de los territorios discursivos.

\section{Agradecimientos}

Este artículo es parte del proyecto de la Universidad de Los Lagos FNI/03/2017 “Fundamentos teóricos metodológicos de los territorios discursivos para el estudio de la poesía mapuche del sur de Chile y de los discursos territoriales del Estado, a comienzos del siglo XXI" y del financiamiento de Becas CONICYT.

\section{Bibliografía}

Lindón, A. 2012. ¿Geografías de lo imaginario o la dimensión imaginaria de las geografías del lebenswelt?, pp. 66-85. En: Lindón y Hiernaux. Geografías de lo imaginario. México: Anthropos.

Lindón, A. 2007. Los imaginarios urbanos y el constructivismo geográfico: los hologramas espaciales. Eure 33(99): 31-46. https://doi.rog/10.4067/S0250-71612007000200004

Morin, E. 1996. Introducción al pensamiento complejo. Madrid: Gedisa.

Ther, F. 2012. Antropología del territorio. Polis 11(32): 493-510. https://doi.org/10.4067/S0718$\underline{65682012000200023}$

Vergara, N. 2009. Complejidad, espacio, tiempo e interpretación. Notas para una hermenéutica del territorio. Alpha 28: 233-244. https://doi.org/10.4067/S0718-22012009000100016

Walsh, C. 2008. Interculturalidad, plurinacionalidad y decolonialidad: las insurgencias políticoepistémicas de refundar el Estado. Tabula Rasa 9: 131-152.

http://www.scielo.org.co/pdf/tara/n9/n9a09.pdf

Recibido el 22 Mar 2018

Aceptado el 15 May 2018 